\title{
The Elective Course Teaching Reform based on Seminar and PBL Mixed Teaching Modes
}

\author{
Bin GUO, Wenxiao WANG, Xuemei BAI \\ Electrical and Electronic Experimental Teaching Center, Changchun University of Science and Technology, \\ Changchun, China
}

\begin{abstract}
Currently, many Chinese college students don't have the clear ideal and are at a loss in the direction of life with narrow range of knowledge. Therefore, it seems that university education reform should be carried out immediately. The paper analyzed the advanced teaching concept and method of Seminar and PBL and implemented some improvement and then combined the two teaching mode to carry out the teaching reform of the elective course.
\end{abstract}

KEYWORD: Seminar; PBL; Elective course system reform; interdisciplinary

\section{INTRODUCTION}

Chinese students have always been in the examoriented education since primary school. Even though colleges, which advocate liberal study, still cannot avoid the plight. Not paying attention in class, high rates of truancy and knowledge forgetting are the learning situation for many university students. Our Current education approaches added some multimedia devices, but the core of the class is still teachers. In other words, the students have not really joined in. Take the teaching material as the stencil. Without question and absorption in a single direction make students gradually lost the ability of active thinking and innovation. This teaching method cut enthusiasm of students' learning interest and curiosity as well as caused the students to lose the initiative of learning. Under such circumstances, the students' learning effect is poor and the quality of teaching can only remain stagnant. Thus, the teaching methods are the decisive factors for the quality of university education in our country, only if carrying out teaching reform constantly, can we keep pace with times and world and realize the aim of facing modernization, world and future education.

\section{SEMINAR TEACHING METHODS}

\subsection{The origin and current application of Seminar}

The real system of Seminar methods was formed at the University of Berlin which was founded from the research thoughts and eventually Seminar has developed into a basic teaching mode and system. Afterwards, successful experiences in Germany were quickly learned by American. Then, England, France, Japan, Greece, Holland, Belgium, Russia, Denmark and other countries have also introduced and applied it in university teaching practice ${ }^{[1]}$.In simple words, seminar is a method of teaching research type. This method of learning efficiency is high, as it can mobilize enthusiasm of students' active thinking, memory of the potential from the three aspects of pre-class, in-class and after- class. If students could search knowledge direction that they are interested in before class, which will greatly increase the learning initiative of students. Then, the discussion in class can stimulate students' potential and imagination and they will pay more attention to the course. In addition, lively debate and speech will form deep memory and enhance learning efficiency. Therefore, after class, better learning habits and scientific thinking ways will be inadvertently cultivated after the logic and scientific learning process. We can see this kind of 3D-interaction (from the types of communicators) will exercise the students' various aspects abilities of learning or research.

About in the 1920's, Seminar was introduced to China. In 1999, the University of Science and Technology of China offered undergraduate with Seminar course and the Seminar teaching method has achieved very good teaching effect according to the survey [1]. Japan has a breakthrough in the practice of this method. In the arrangement of the Nihon University, the elementary Seminars were set 
at the first year set and professional Seminars were offered at the second year. While some universities offered professional Seminar in the third year. The type of combing basic Seminar with professional Seminar can make students adapt to the study process step by step from comprehension, realization, and imitation to the real practice and therefore, it can lay a good foundation for future work and learning.

\subsection{The shortcomings and improvements of Seminar}

From the experience of Japan's Seminar, we can try to reform the system of elective courses. In our existing system of elective courses unilaterally offered elective direction and the model of class was single and boring, which cannot arouse the students' interest and innovative ideas. Many students study just for credit. All those factors cannot implement the teaching goals of the elective course and the purpose of the elective class has a discount. Therefore, it is also very necessary and appropriate to introduce seminar to the elective course besides the basic course study. For example, we can have a discussion in a certain field with the most recent theoretical studies to identify the operation effectiveness of problem solving or put forward your ideas about the question. Please take note of not constraining your mind in the specialty and the discipline, the diversification ways of solving problems can further open up their vision and creativity. Especially in the interdisciplinary times, it is crucial to learn how to implement integration and migration.

However, Seminar is not all-purpose. The teachers' guidance role is still very important even if students become the main part of the class. When questions appeared during the topic and discussions, the teacher should solve them in a certain range. This requires that teachers have erudite and accurate professional knowledge and they also should have the ability to inspire the divergent thinking, make the students absorb the knowledge in a relaxed and pleasant environment and be a good leadership. On the other hand, if the teachers cannot work out questions in a certain period of time, there is no doubt that it will cause the students' disappointments to the teacher and will have a negative psychological to the direction of knowledge. In addition, if the teachers have not guided accurately during the Seminar schedule, it will not only make the problem unsolved, but also let the students' thinking in confusion. Therefore in my opinion, a careful selecting teacher for elective courses is very important.
From the students' perspective, less communication within group will produce a series of problems. In addition, we need to pay attention to the disciplines' difference and the teaching forms may be different for different disciplines. For example, the teaching form of science cannot be completely consistent with liberal arts and the forms of debate and discussion should only be based on the students who master the theory of knowledge. Maybe, some group discussion should be carried out after class otherwise it will delay the progress of the course.

\section{PBL TEACHING METHOD}

\subsection{The origin and current application of PBL}

In fact, PBL and Seminar are quite similar. Problembased learning, which can be called as PBL, was set up at McMaster University of Canada in 1960's. it is called a method of constructing curriculum, which was prepared for the actual combat practice only for helping medical students in learning. After 40 years of development, PBL has been extended in many fields [3]. Such as architecture, psychology, education, engineering and etc. As we can see, the method is very effective in social application subject. Moreover, there are many foreign schools that use the method to make thinking expanded and developed.

PBL essentially set the learning in a complex and meaningful problem situation and the complicated, practical or authentic problem should be solved jointly by students who work together in a group. The key is to learn the scientific knowledge which is hidden behind problems and to strengthen the ability of solving problems, self-study and lifelong learning [4]. It also reflected that practice is the sole criterion for testing truth. Therefore, we can see that the focus of PBL is the autonomy of the students, which includes searching information autonomy, self-study and independence thinking. During this process, the students' practical ability and thinking ability will be enhanced and the theoretical foundation of knowledge will be verified to a certain extent. This will strengthen the understanding of knowledge and memory, which will also gain a sense of achievement and students will continue to motivate themselves into practice and the virtuous cycle of self-study.

\subsection{The shortcomings and improvements of PBL}

The points that PBL should be paid attention are similar with that of Seminar-method. PBL is a kind of learning mode based on solving practical problems and therefore PBL can be used as a 
summary of a class or extracurricular practice writing. The curriculum situation should be based on groups. Students are divided into groups given the deadline and each group can choose problems and put forward proposals and schemes to solve the problem. For some majors with practical ability requirements, students should be given certain teaching environment and conditions. Thus, students can improve their manipulative ability, which will get rid of empty talk.

Teachers should have rich experience in the practice of knowledge and make it possible to guide students to a certain extent. And the most important thing is that teachers and students should learn together. When teachers meet with their unfamiliar fields, they can face them with an open mind and set a good example for students. In addition, a series of discussion will be idle work, if the proposed direction had been deviation from the beginning, which must discourage students to continue exploring questions of issues and practice.

\section{COMBINING SEMINAR-METHOD WITH PBL}

We observed from internet that the harmony and deep communication between teachers and students in Notecase Open Course of famous foreign universities. Therefore, the core of the reform of teaching methods is to improve student interests and increase the participation of students' firstly. The teaching reform should try to make students keep the maximum of aspiration to knowledge.

As said before, Seminar and PBL can be carried out at the same time. Seminar can be used as a realtime theory teaching in class and PBL can be used as a summary of subject. Both methods have different aims and supplement each other again. Seminar can be implemented after class aiming at the stage of knowledge and putting forward the problems and ideas of their own. Students can solve one or more problems with the latest papers or data and study the expanding knowledge. Gradually, the students will extend the scope of their minds. During the seminar, teachers could recommend relevant information in time, guide students to find information themselves and select the parts that are used for their own. PBL could be carried out at the end of the course to focus on exploring the practical problems. Teachers or students raise questions. Then students find implementation schemes with packed speech instructions and come up with convinced evidence or practical results. Finally teachers and classmates decide the optimum scheme with modification and evaluation.

Certainly, these two methods will encounter many unexpected problems during the implementation process, such as curriculum arrangements and teachers' assignments, classification of issues according to students' interest and applications of interdisciplinary variety. Especially, there will be some barriers in correcting students' bad study habits and attitudes. Also, communication among team members also need pay enough attention. In addition, the discussion about the problems may be associated with personal emotional value, so this requires specialized courses counseling as well as correct guidance of psychological counseling by teachers. The target of teaching students in accordance with their aptitude is the destiny and the most important thing for students is to realize the importance of the interest and learning.

\section{CONCLUSION}

The teaching scheme combined Seminar with PBL is implemented in elective course for the students of electronic and information engineer major. According to the survey questionnaire, the students reflected that this kind of teaching method was more flexible and they feel the classroom's atmosphere is no longer rigid and learning can be freer. They don't have to steal time to learn researching directions they like outside the classroom and they can put them in class together with like-minded members of the group to discuss the discipline contends. In this way, the learning efficiency has been improved greatly and more creative ideas are introduced.

\section{REFERENCES}

[1] Rongqun Chen, Ying Tian, Yunguang Long \& Tieyan Fu. Application Research on Seminar teaching method Under the Environment of Education Information, China Audiovisual Education. 2014.2, Vol. 325

[2] Jincong Liu. A Probe into the Application of Japanese Seminar Course Teaching Mode in China, Journal of Guangdong University of Foreign Studies, 2008.9, Vol.19

[3] Xiaoli Wang. Application and Effect Analysis of PBL and Seminar Teaching Mode in Pharmaceutical Experimental Teaching. Journal of Qiqihar University of Medicine, 2011, Vol.32

[4] Xiaoyan Liu. Research on Problem Based Learning mode. Postgraduate degree thesis, School of Communication Studies, Jiangxi Normal University, 2002.5 